\title{
Particle image velocimetry and digital image correlation for determining the elasticity
} modulus in wood

\author{
Cássio Humberto Lima*(), Francisco Carlos Gomes ${ }^{\circledR}$, Rodrigo Allan Pereira®, Fernando Pujaico Rivera®
}

Universidade Federal de Lavras - Depto. de Engenharia Agrícola, C.P. 3037 - 37200-900 - Lavras, MG - Brasil. *Corresponding author <cassiohead@hotmail.com>

Edited by: Thiago Libório Romanelli

Received December 08, 2020

Accepted August 12, 2021
ABSTRACT: Several non-destructive testing techniques have been improved and tested in recent years. The non-destructive testing techniques using particle image velocimetry (PIV) and digital image correlation (DIC) differ from conventional testing techniques, as they allow making measurements indirectly. In this study, the elastic modulus in wood beams of Eucalyptus grandis and Pinus oocarpa were determined using PIV and DIC. The application of PIV and DIC techniques occurred during the static bending tests, when the displacements were also measured by the conventional method. The applied load values allowed calculating the elasticity modulus. In all regions of analysis, the mean values of the elasticity modulus found by the DIC, PIV and conventional method are statistically equivalent. It is concluded that the PIV and DIC testing techniques can be used to determine mechanical properties of wood.

Keywords: non-destructive tests, elastic modulus, displacements

\section{Introduction}

The non-destructive testing techniques are an alternative to conventional material characterization, as these techniques do not modify the material structure in a way that compromises its final use after the tests (Carrillo et al., 2019).

For some time, non-destructive methods have been used to characterize different materials (Ettelaei et al., 2019; Osuna-Sequera et al., 2019). There are several techniques for non-destructively to assess the mechanical strength of materials, such as measuring the speed of sound propagation by striking the sample with a hammer or even analyzing the speed and amplitude of sound propagating throughout the material of a wooden beam (Souza et al., 2014).

The particle image velocimetry (PIV) technique allows obtaining the deformation from specific points in the material and is thus capable of measuring the mechanical properties. Thus, information on deformation provides important data about the material studied (Willert and Gharib, 1991).

The Digital Image Correlation (DIC) technique uses the correlation analysis to examine digital images captured in various loading scenarios. Consecutive images are captured with a digital camera during the deformation period of the material under study and changes in material surface characteristics are recorded and evaluated (Pereira et al., 2018).

The PIV and DIC techniques are non-destructive optical testing techniques that can be applied to service structures (in loco), becoming options to obtain reliable results of the mechanical behavior of materials subjected to loading, such as wood (Pereira et al., 2018).

Braga Junior (2015) used the PIV technique in a study to monitor deformations of a steel beam (cantilever type ASTM A36). The material surface particles were illuminated with a laser and the successive images during loading displayed the deformation undergone by the material using the PIV technique. The deformation data and the optimization of the PIV algorithm allowed calculating the Young's modulus.

Tin this study, the elasticity modulus in Eucalyptus grandis and Pinus oocarpa wood specimens using the PIV and DIC techniques were determined, and their accuracy and applicability in relation to the conventional testing technique were verified.

\section{Materials and Methods}

Two wood species, 30 specimens of Pinus oocarpa and 30 specimens of Eucalyptus grandis, were used. All specimens complied with the standards of the American Society for Testing and Materials (1995) ASTM D14394 with dimensions of $0.41 \times 0.025 \times 0.025 \mathrm{~m}$ (length, width and thickness). The standard was chosen because the dimensions of the specimens are smaller than the Brazilian standard thus allowing a greater number of specimens and were then conditioned at $22 \pm 2{ }^{\circ} \mathrm{C}$ and relative humidity $65 \pm 5 \%$. The experiment was carried out in Lavras, state of Minas Gerais, Brazil (21 ${ }^{\circ} 13^{\prime} 44^{\prime \prime} \mathrm{S}$, $44^{\circ} 58^{\prime} 27^{\prime \prime} \mathrm{W}$, and $930 \mathrm{~m}$ asl).

The specimens were subjected to static bending tests in a Universal Testing Machine - UTM $1300 \mathrm{kN}$ load capacity, force measurement accuracy: meets or exceeds Class 1 per NM ISO 7500-1 from 2 to $100 \%$ of the rated capacity of the load cell in use) and the PIV and DIC techniques were applied to determine the elasticity modulus. The UTM was instrumented with dial indicators (one in the center of the specimens and two at half of the distance between the supports and the load application point) (Figures $1 \mathrm{~A}, 1 \mathrm{~B}$, and $1 \mathrm{C}$ ) to measure the displacement values of the beams of the specimens.

A professional digital camera positioned perpendicularly to the specimen surface $(0.30 \mathrm{~m})$ was 


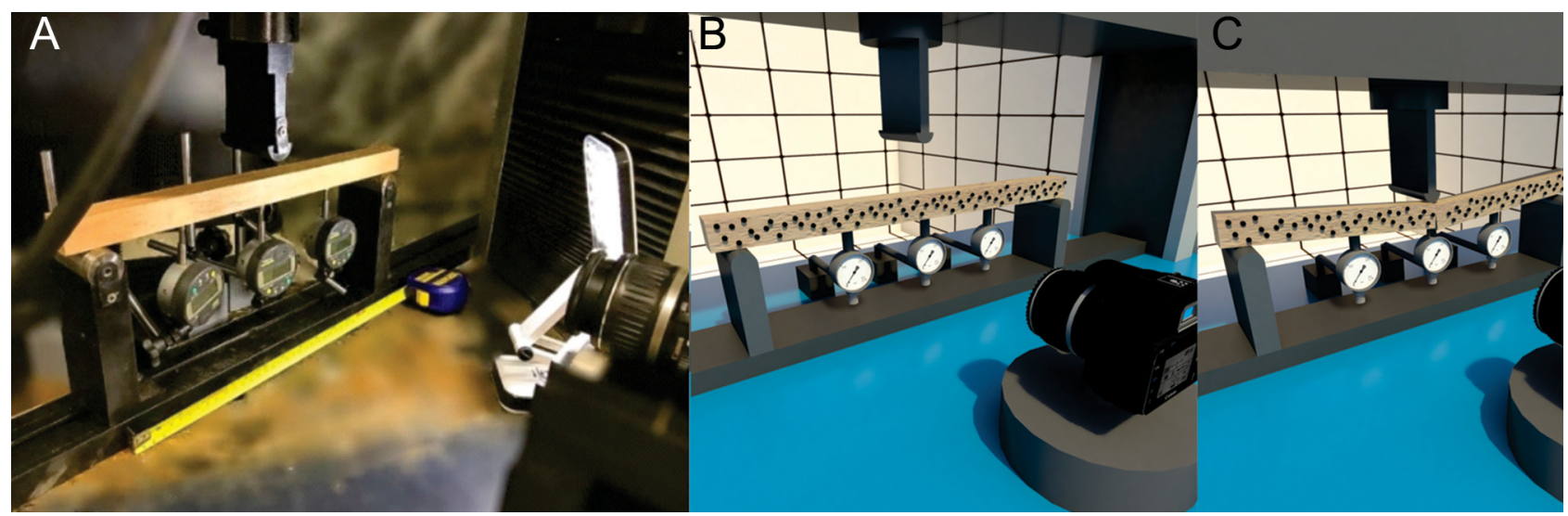

Figure 1 - Experimental setup: (A) Experiment photo (B) Schematic of camera positioning in relation to specimen before loading (C) Schematic of camera positioning in relation to specimen after loading. Credit: Cássio Humberto Lima.

used to capture the images. The camera was equipped with a lens assembly for better focus adjustment on the specimen surface (Figures 1A, 1B, and C). Images were captured using a remote control to avoid any camera disturbance. A luminary was used to ensure a better result at the time of image capture. Figures $1 \mathrm{~A}, 1 \mathrm{~B}$, and $1 \mathrm{C}$ show the instrumentation for the tests.

The average duration of each static bending test for Eucalyptus grandis and Pinus oocarpa specimens was 600 and $400 \mathrm{~s}$, respectively. Loading speed was $1.3 \mathrm{~mm}$ $\mathrm{min}^{-1}$ as specified of the American Society for Testing and Materials (1995) ASTM D143-94.

The surface of the specimens was marked with black ink (Figures 2A and 2B) to allow, during the image processing by the PIV and DIC methods, the algorithms to identify the regions of interest and thus measure their displacements according to the load application on the static bending test. In each interrogation window, pairs of particle images (painted dots) are searched for and tracked in subsequent images. The distribution adopted for the markers was the random distribution, with a point density of 0.0085 points $\mathrm{m}^{-2}$. The mean diameter of the points was $0.002 \mathrm{~m}$ (Figures $2 \mathrm{~A}$ and $2 \mathrm{~B}$ ).

For the application of the PIV and DIC techniques, the first image was captured before starting the loading (time $=0$, displacement $=0$ ) and the other images were captured according to a pre-established time interval of $30 \mathrm{~s}$. Thus, the first image served as a benchmark for subsequent images. The PIV and DIC techniques were performed concurrently with the static flexion test (Pereira et al., 2018).

During the tests, the UTM recorded four data inputs of parameters in $60 \mathrm{~ms}$ such as time, force, table position and displacement. For a trial of approximately $420 \mathrm{~s}$, the UTM records about 7500 data per parameter, while the analysis of the captured images yields about 15 data (in case of image capture every $30 \mathrm{~s}$ ). Thus, data from the UTM were used at the same time as the images were captured.

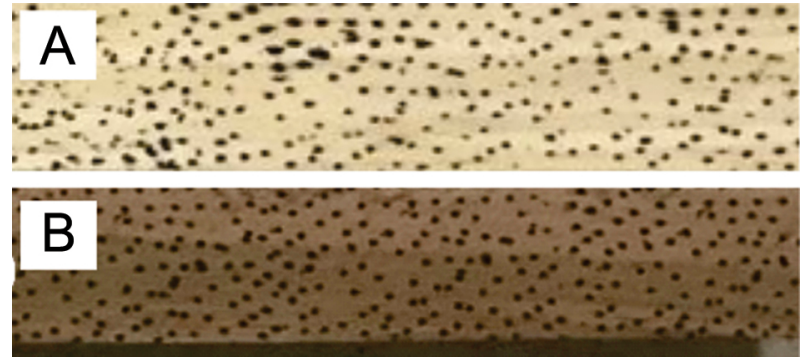

Figure 2 - Specimens with random markers: (A) Pinus oocarpa, (B) Eucalyptus grandis. Credit: Cássio Humberto Lima.

Subsequent to the tests, the captured images were processed in the Image $\mathrm{J}$ image processing software, according to the methodology adopted by Pereira et al. (2018). The images were scaled down to $25 \%$ of the original size (3888 $\times 2592$ pixels to $972 \times 948$ pixels $)$ and each image was converted to eight bits in grayscale. All of these conversions aimed to reduce and thus decrease their processing time in the PIV and DIC algorithms.

For the application of the PIV technique, the following settings were used in the PIV algorithm: $32 \times 32$ pixel interrogation window, one pixel search arm, 50-pixel analysis region and the interrogation window correlation similarity threshold was 0.82 . For the application of the DIC technique in the Ncoor algorithm, we used a 32-pixel diameter interrogation window and a 2-pixel search arm.

After processing the images in the PIV and DIC algorithms, the displacement values were obtained for the chosen locations for the analysis. This procedure intended to calculate the displacements of interrogation windows positioned in the unloaded image relative to subsequent photos (Figures $3 \mathrm{~A}$ and $3 \mathrm{~B}$ ).

We used the free software GNU Octave to process all images by the DIC technique in conjunction with the ncoor algorithm, while the pivmake-gui algorithm was used for the PIV technique, both aiming to obtain 


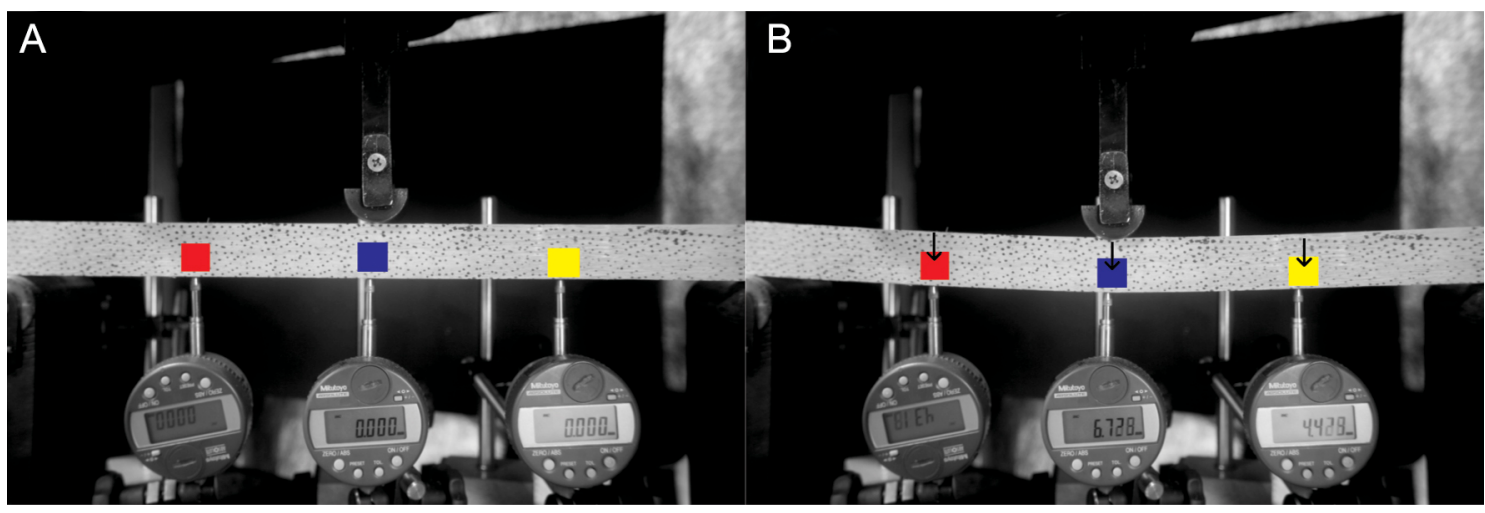

Figure 3 - Selection of interrogation windows in PIV algorithm: (A) Before loading (B) After loading. Credit: Cássio Humberto Lima.

the displacement in each of the regions of interest of the images under study. The deformed images were compared with the reference image, correlating all the pixels of the regions of interest.

After processing the images in the appropriate algorithms, the displacement values were obtained for the locations chosen for the analysis. In this case, the regions chosen were close to the dial indicators in three different positions (left, center and right). Based on of the American Society for Testing and Materials (1995) ASTM D143-94, the displacement values of the central part of the specimen were used to calculate the elasticity modulus.

We obtained the loading values applied by the UTM for each specimen with the displacements obtained by the PIV, DIC and dial indicator. Thus, the elasticity modulus in each specimen of each material was calculated using the PIV, DIC techniques and the conventional method. The elasticity modulus was determined by the slope of the secant line to the load $\times$ displacement curve in the mid-span, with the deformation values calculated by the PIV, DIC algorithms and the load values obtained from the UTM, according to the American Society for Testing and Materials (1995) ASTM D143-94.

The calculation of the elasticity modulus, a span-depth ratio $\left(\mathrm{L} \mathrm{h}^{-1}\right)$ of approximately $100 \pm 10$ is recommended as established by the American Society for Testing and Materials (1995) ASTM D4761-19, for a long span static bending test configuration. The span-depth ratio in the test conducted in this work was 14, thus indicating the need to consider the shear deflection effect. According to Ozyhar et al. (2012), increasing $\mathrm{E}_{\mathrm{m}}$ values (elasticity modulus in static bending) by $10 \%$ corrects the effect of shear deflection in the tested material. The values of modulus of elasticity determined from bending $\left(\mathrm{E}_{\mathrm{m}}\right)$ are calculated according to Eq. (1).

$E_{M 0}=\frac{\left(F_{M, 50 \%}-F_{M, 10 \%}\right) * L^{3}}{\left(v_{50 \%}-v_{10 \%}\right) * 4 * b * h^{3}}$

In which: $F_{M, 50 \%}$ and $F_{M, 10 \%}$ are the loads corresponding to $10 \%$ and $50 \%$ of the estimated maximum load applied to the specimen, in Newtons $v_{10 \%}$ and $v_{50 \%}$ are mid- span displacements corresponding to $10 \%$ and $50 \%$ of the estimated maximum load $F_{M, e s t}$ in meters; b and h correspond, respectively, to the width and height of the cross-section of the test piece, in meters.

After comparing the results obtained by the conventional method and by the PIV and DIC techniques, it was necessary a statistical verification of the values found by the techniques under study. We performed the analysis of variance (ANOVA), a statistical procedure that allows comparing the three methods under study, PIV, DIC and conventional method.

The ANOVA was performed comparing the conventional technique and the PIV and DIC techniques, applying the $\mathrm{F}$ test with $95 \%$ confidence level, and formulating the following hypotheses: $\mathrm{H}_{0}$ : the means of the methods are equal; and $\mathrm{H}_{1}$ : At least one of the means of the methods is different.

$\mathrm{H}_{0}$ refers to the null hypothesis and $\mathrm{H}_{1}$ the alternative hypothesis. The analysis of variance detects differences between the mean values obtained in the methods. If the null hypothesis is rejected, it is necessary to apply the Scott-Knott test, at $95 \%$ confidence level, to identify which method presented difference between the other methods.

\section{Results and Discussion}

After the static bending tests, the displacement values were obtained for each Eucalyptus grandis and Pinus oocarpa specimens, generating three sets of values containing the deformations during the tests, one by the conventional method (MC), one by the PIV technique, and another by the DIC technique. The elasticity modulus was calculated by the three methodologies. In all tests the PIV and DIC techniques had elastic modulus values very close to those found by the conventional method (Figures 4A and 4B).

A linear regression was made from the comparison of the results obtained by the PIV and DIC techniques and conventional method (Figures 5A, 5B, 5C, and 5D). The regression analysis of samples provided correction equation of the type " $\mathrm{y}=\mathrm{ax}+\mathrm{b}$ " and coefficient of 

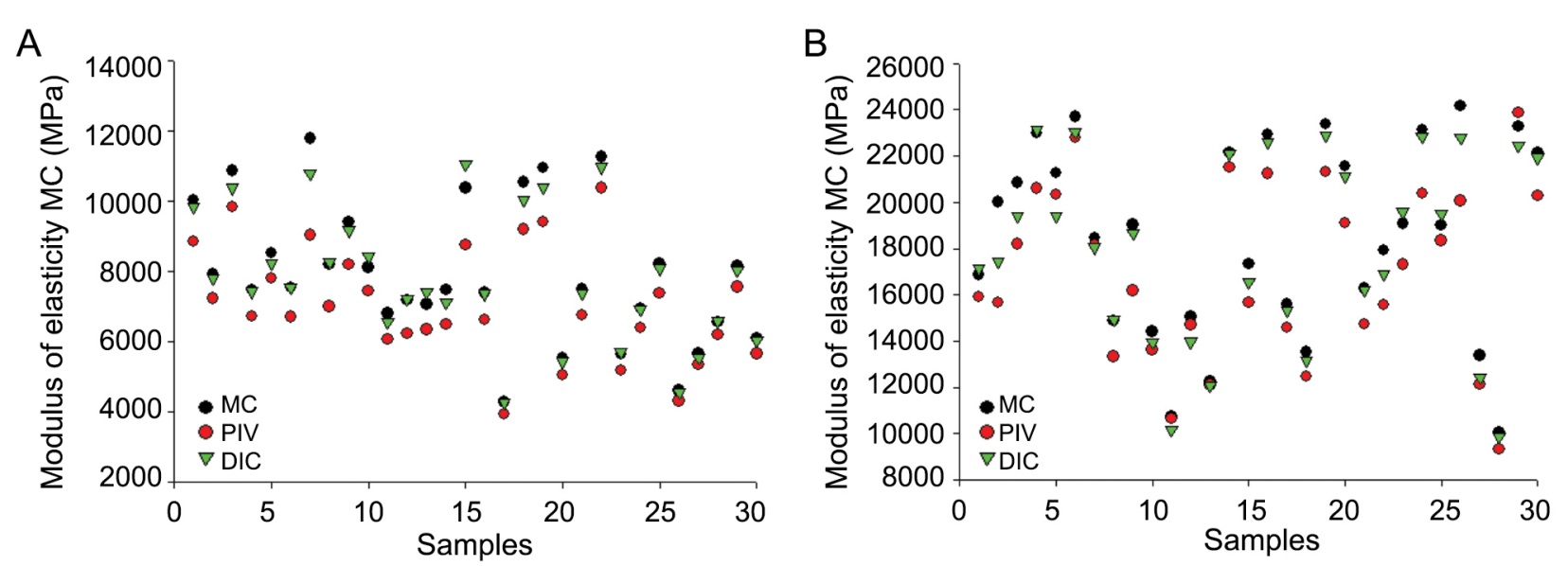

Figure 4 - Comparison of the values of the elasticity modulus obtained by the conventional technique and by the techniques of particle image velocimetry (PIV) and digital image correlation (DIC): (A) Pinus oocarpa (B) Eucalyptus grandis.
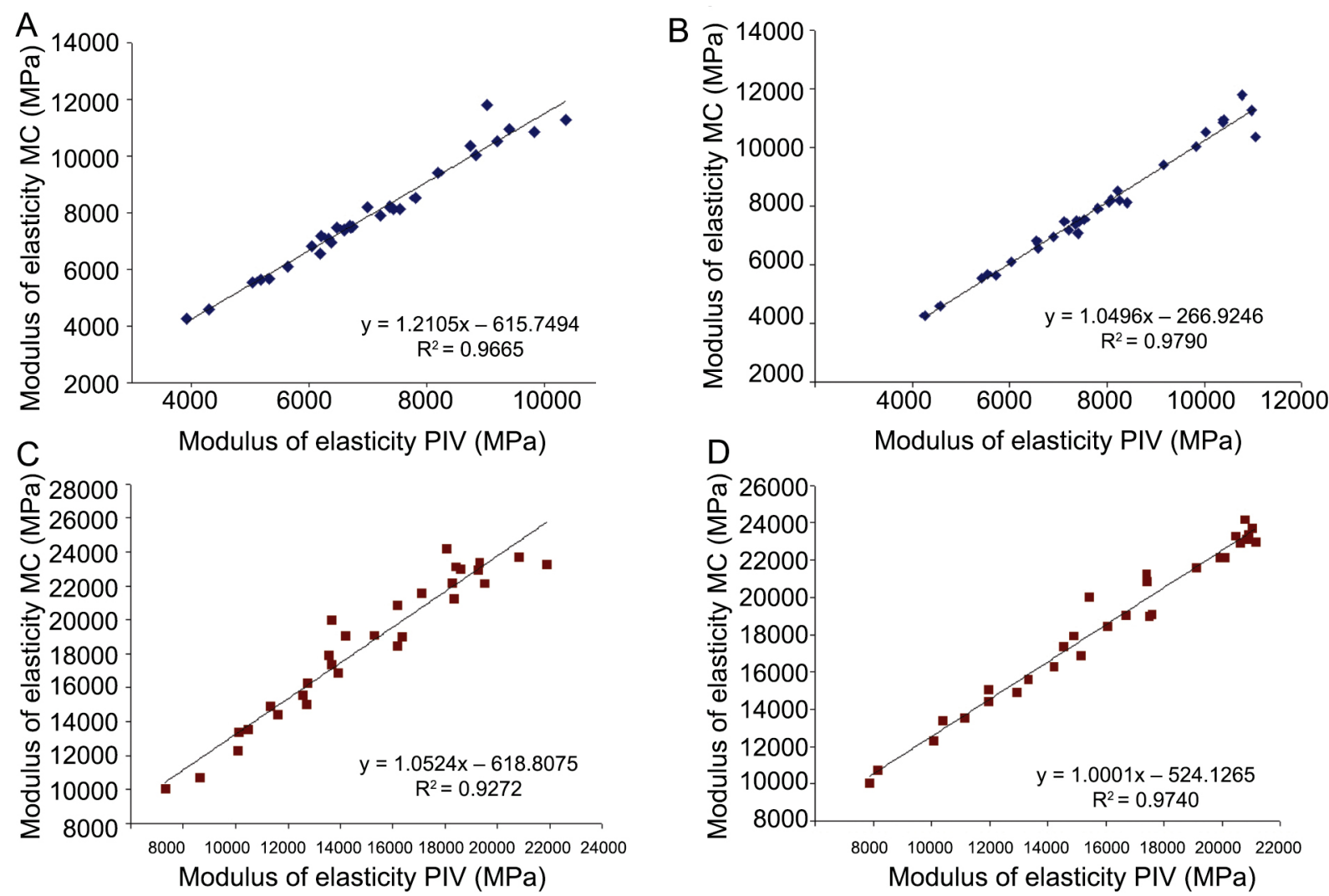

Figure 5 - Linear regression of the values of the elasticity modulus obtained by the conventional technique (y axis) and by the techniques of particle image velocimetry (PIV) and digital image correlation (DIC) (x axis): (A) Pinus oocarpa with the PIV technique (B) Pinus oocarpa with the DIC technique (C) Eucalyptus grandis with the PIV technique (D) Eucalyptus grandis with the DIC technique.

determination $\mathrm{R}^{2}$. Values of $\mathrm{R}^{2}$ were above 0.92 thus showing a high correlation between the values obtained in both datasets.

Guedes et al. (2019) conducted a study on the elasticity modulus of wooden beams and obtained coefficients of determination $\mathrm{R}^{2} 0.72$ for Cedrela spp. and 0.75 for Eucalyptus cloeziana, indicating a correlation between the values when comparing the conventional with the PIV technique. The same occurred in our study, which presented $\mathrm{R}^{2}$ always higher than 0.92 .

Pereira et al. (2019) studied the measurement of displacement in saw wood and panel wood using 
the particle image velocimetry technique and found $R^{2}$ values always higher than 0.90 , indicating a high correlation when comparing the PIV with the conventional technique, similar to our results.

Souza et al. (2014) investigated non-destructive testing techniques using sunset laser and PIV to obtain deformation maps to predict failures in wood structures and obtained $\mathrm{R}^{2}$ values above 0.86 , indicating a high correlation between the values from the conventional and the PIV technique, similar to our results.

After obtaining the determination coefficients, the statistical analysis was performed comparing the conventional and the PIV and DIC techniques, applying the Scott-Knott test with a $95 \%$ confidence level (Table 1). Table 1 presents the average results of the elasticity modulus obtained by the three techniques: PIV, DIC and conventional in Eucalyptus grandis and Pinus oocarpa woods.

The results of the elasticity modulus in Table 1 were obtained by the average values of the 30 specimens for each wood species under study. The ANOVA showed that the results of the elasticity modulus were not different $(p<0.05)$, when comparing the three techniques thus indicating precision and reliability of the PIV and DIC techniques in relation to the conventional method.

Several authors have determined the mechanical properties of Eucalyptus grandis. Carrasco et al. (2016) conducted a study on the elasticity modulus in wood of eucalyptus hybrids and found a mean value of 12,715 $\mathrm{MPa}$. In our study, we found 17,284.93 MPa by PIV and 18,362.97 MPa by DIC.

The values obtained for the static elastic modulus of Eucalyptus grandis wood (Table 1) are in accordance with those presented in Brazilian Standard NBR 7190 - Projects in Timber Structures - of the Brazilian Association of Technical Standards (1997) ABNT NBR 7190-97 for the genus. Eucalyptus, ranging from 12,813 to $19,881 \mathrm{MPa}$.

Segundinho et al. (2017) studied the determination of the elasticity modulus of Pinus sp. in non-destructive tests of free transverse vibration and found a value of the elasticity modulus of 7,500 $\mathrm{MPa}$. Trianoski et al. (2014) presented a value of the elasticity modulus of
7,993.0 MPa for Pinus oocarpa, values similar to our findings.

Missio et al. (2013) used the ultrasonic method to estimate the elasticity modulus of Pinus taeda woods and obtained an average result of 9,068.22 $\mathrm{MPa}$, higher than the values in our study. This can be explained by the anatomical medications in the wood after the treatments.

Stangerlin et al. (2008) carried out a study to correlate the elasticity modulus obtained by destructive and non-destructive methods of Eucalyptus grandis and Pinus elliotti woods and the mean value of the elasticity modulus the method observed by ultrasound was 15,698 $\mathrm{MPa}$ and $10,501 \mathrm{MPa}$, respectively and the means of parallel compression test with Eucalyptus grandis and Pinus elliotti wood fibers were 13,119 $\mathrm{MPa}$ and 8,739 $\mathrm{MPa}$, again similar to the values found in our study.

Pereira et al. (2018) conducted a study to obtain the elasticity modulus by the conventional and nondestructive testing technique (PIV) and found an average value of the elasticity modulus of 7,062.63 MPa for Pinus oocarpa, a value lower than that found in our study. The materials used by the authors are commercial; however, the values found by the conventional methodology were statistically equal to those found using the PIV technique. Regardless of the value, the same occurred in our study, where the values of the elasticity modulus had static equality for the three techniques: PIV, DIC, and conventional.

\section{Conclusions}

The elasticity modulus obtained by the three test methods (MC, PIV and DIC) were not different.

The PIV and DIC techniques to obtain the elasticity modulus provided results as accurate as the results found by the conventional technique.

\section{Acknowledgments}

We thank the Federal University of Lavras, Coordination for the Improvement of Higher Level Personnel (CAPES), Minas Gerais State Agency for Research and Development (FAPEMIG) and Brazilian National Council for Scientific and Technological Development (CNPq).

Table 1 -The analysis of variance and the Scott-Knott test for the comparison of values of the elasticity modulus between the particle image velocimetry (PIV), the digital image correlation (DIC), and the conventional method (MC) at $5 \%$ significance level.

\begin{tabular}{|c|c|c|c|c|c|c|}
\hline \multirow{2}{*}{ Samples } & \multirow{2}{*}{ Methods } & \multicolumn{3}{|c|}{ Analysis of variance among methods } & \multirow{2}{*}{ Average Elasticity Module (MPa) } & \multirow{2}{*}{ Test Scott-Knott * * } \\
\hline & & Variation coefficient CV (\%) & FC & $\operatorname{Pr}>\mathrm{FC}^{*}$ & & \\
\hline \multirow{3}{*}{ Eucalyptus grandis } & PIV & \multirow{3}{*}{23.44} & \multirow{3}{*}{1.111} & \multirow{3}{*}{0.3339} & $17,284.9288$ & A 1 \\
\hline & DIC & & & & $18,362.9758$ & A 1 \\
\hline & MC & & & & $18,894.2951$ & A 1 \\
\hline \multirow{3}{*}{ Pinus oocarpa } & PIV & \multirow{3}{*}{24.03} & \multirow{3}{*}{2.001} & \multirow{3}{*}{0.1413} & $7,062.6340$ & B 1 \\
\hline & DIC & & & & $7,812.8533$ & B 1 \\
\hline & MC & & & & $7,933.6063$ & B 1 \\
\hline
\end{tabular}

* Significant F test at $95 \%$ confidence level; * ${ }^{*}$ Scott-Knott test: means followed by the same letter and number correspond to statistically equal methods. The means correspond to statistically different methods at $95 \%$ confidence level when followed by different letters and numbers. 


\section{Authors' Contributions}

Conceptualization: Lima, C.H.; Gomes, F.C.; Pereira, R.A. Data acquisition: Lima, C.H.; Pereira, R.A.; Gomes, F.C. Data analysis: Lima, C.H.; Rivera, F.P. Design of methodology: Lima, C.H.; Gomes, F.C.; Pereira, R.A. Writing and editing: Lima, C.H.; Pereira, R.A.

\section{References}

American Society for Testing and Materials [ASTM]. 1995. ASTM D143-94 - Standard Methods of Testing Small Clear Specimens of Timber. ASTM, West Conshohocken, PA, USA.

American Society for Testing and Materials [ASTM]. 1995. ASTM D4761-19 - Standard Test Methods for Mechanical Properties of Lumber and Wood-Based Structural Materials. ASTM, West Conshohocken, PA, USA.

Associação Brasileira de Normas Técnicas [ABNT]. 1997. ABNT NBR 7190-97. Wood Structure Projects = ABNT NBR 7190-97. Projeto de Estruturas de Madeira. Rio de Janeiro, RJ, Brazil (in Portuguese).

Braga Junior, R.A.; Magalhaes, R.R.; Melo, R.P.; Gomes, J.V. 2015. Maps of deformations in a cantilever beam using particle image velocimetry (PIV) and speckle patterns. Rem: Revista Escola de Minas 68: 273-278. https://doi.org/10.1590/037044672013680016

Carrillo, J.; Ramirez, J.; Lizarazo-Marriaga, J. 2019. Modulus of elasticity and poisson's ratio of fiber-reinforced concrete in Colombia from ultrasonic pulse velocities. Journal of Building Engineering 23: 18-26. https://doi.org/10.1016/j. jobe.2019.01.016

Ettelaei, A.; Layeghi, M.; Hosseinabadi, H.Z.; Ebrahimi, G. 2019. Prediction of modulus of elasticity of poplar wood using ultrasonic technique by applying empirical correction factors. Measurement 135: 392-399. https://doi.org/10.1016/j. measurement.2018.11.076

Guedes, T.O; Pereira, R.A.; Rivieira, F.P.; Silva, J.R.M.D. 2019. Particle Image velocimetry for estimating the young's modulus of wood specimens. Cerne 25: 240-245. https://doi.org/10.1590 /01047760201925022633

Missio, A.L.; Gatto, D.A.; Modes, K.S.; Santini, E.J.; Stangerlin, D.M.; Calegari, L. 2013. Ultrasonic method for estimating the modulus of elasticity of heat-treated Pinus taeda woods. Ciência Rural 43: 616-622.
Osuna-Sequera, C.; Llana, D.F.; Esteban, M.; Arriaga, F. 2019. Improving density estimation in large cross-section timber from existing structures optimizing the number of non-destructive measurements. Construction and Building Materials 211: 199206. https://doi.org/10.1016/j.conbuildmat.2019.03.144

Ozyhar, T.; Hering, S.; Niemz, P. 2012. Moisture-dependent elastic and strength anisotropy of European beech wood in tension. Journal of Materials Science 47: 6141-6150. https:// doi.org/10.1007/s10853-012-6534-8

Pereira, R.A.; Gomes, F.C.; Braga Júnior, R.A.; Rivera, F.P. 2018. Analysis of elasticity in woods submitted to the static bending test using the particle image velocimetry (PIV) technique. Engenharia Agrícola 38: 159-165. https://doi.org/10.1590/18094430-eng.agric.v38n2p159-165/2018

Pereira, R.A.; Gomes, F.C.; Braga Júnior, R.A.; Rivera, F.P. 2019. Displacement measurement in sawn wood and wood panel beams using particle image velocimetry. Cerne 25: 110-118. https://doi.org/10.1590/01047760201925012619

Segundinho, P.G.D.A.; Carreira, M.R.; Regazzi, A.J.; Dias, A.A. 2017. Influence of moisture content on the determination of the modulus of elasticity of Pinus sp. beams. Ambiente Construído 17: 319-329. https://doi.org/10.1590/s1678-86212017000300179 (in Portuguese, with abstract in English).

Souza, T.M.; Contado, E.W.; Braga, R.A.; Barbosa, H.C.; Lima, J.T. 2014. Non-destructive technology associating PIV and Sunset laser to create wood deformation maps and predict failure. Biosystems Engineering 126: 109-116. https://doi.org/10.1016/j. biosystemseng.2014.08.004

Stangerlin, D.M.; Calegari, L.; Santini, E.J.; Domingues, J.M.; Gatto, D.A.; Melo, R.R. 2008. Determination of the modulus of elasticity in wood using destructive and non-destructive methods. Revista Brasileira de Ciências Agrárias 3: 145-150 (in Portuguese, with abstract in English).

Trianoski, R.; Matos, J.D.; Iwakiri, S.; Prata, J.G. 2014. Evaluation of mechanical properties of wood from tropical Pinus species. Scientia Forestalis 42: 21-28 (in Portuguese, with abstract in English).

Willert, C.E.; Gharib, M. 1991. Digital particle image velocimetry. Experiments in Fluids 10: 181-193. https://doi.org/10.1007/ BF00190388 